American Journal of Pharmacology and Toxicology 4 (4): 165-168, 2009

ISSN 1557-4962

(C) 2009 Science Publications

\title{
A Comparative Study between Abdominal and Laparoscopic Diathermy in Evaluation of Ovulatory Response in Women with Polycystic Ovary Syndrome
}

\author{
Nabila K. Yaaqoub, Enas M. Yaseen and Ruqiya S. Tawfeek \\ Department of Gynecology and Obstetrics, Faculty of Medicine, University of Tikrit, \\ P.O. Box 42, Tikrit Salahuddin, Iraq
}

\begin{abstract}
Problem statement: To compare the effects of both abdominal and laparoscopic diathermy (PCOS) on the ovulatory process. Design: Prospective study. Setting: Tikrit Teaching Hospital, Iraq. Approach: A total of 40 infertile patients, these patients were divided into two groups, each group of 20 patients. The first group was undergoing abdominal diathermy; while the second group undergoing laparoscopic diathermy. The ovulatory response were assessed by both LH and testosterone levels. Results: After Diathermy, there were significant effects on regularity of menses: $25 \%$ in first group had regular cycle and in second group $60 \%$ had regular cycle. Decrease in LH and testosterone Level after surgery were significantly different in both groups: $35 \%$ in first group and $70 \%$ in second group. Conclusion: Laparoscopic diathermy showed higher rates of regular resumption of menses and decrease in LH and testosterone level than abdominal diathermy.
\end{abstract}

Key words: Laparoscopic diathermy, abdominal diathermy, ovulatory response, PCOS

\section{INTRODUCTION}

Infertility is the inability of a couple to obtain a clinically recognizable pregnancy after 12 months of normal marital relationship (regular unprotected intercourse). It is classified into primary and secondary types. Primary is for those who have never conceived in the past and secondary for those who have conceived in the past regardless the outcome of pregnancy ${ }^{[1]}$.

Infertility affects approximately $10-15 \%$ of couples at reproductive age. Female factor of infertility has a prevalence of $40-55 ; 14 \%$ of all infertility causes are related to tubal factor; while $75-80 \%$ of patients with PCOS are complain from an ovulatory infertility ${ }^{[2]}$.

Polycystic ovary syndrome is a commonly diagnosed female endocrinopathy particularly in the young women, although its etiology remains unknown [3,4].

The evaluation of an infertile couple commonly begins with non invasive tests such as pelvic examination, basal body temperature charts, semen analysis and post coital test and later tests for assessing uterine and tubal abnormalities such as endometrial biopsy and Hystero Salpingography (HSG) are performed $^{[5]}$.

The prevalence of symptomatic PCOS of 5-10\%; whereas asymptomatic PCOS is reported to be as high as $20-25 \%$ in women of reproductive age ${ }^{[6,7]}$.
PCOS was first described in 1935 by Stein and Leventhal. They described the dramatic effects of ovarian wedge resection in seven women with enlarged PCO who complained of oligomenorrhoea or amenorrhoea $^{[8]}$.

The Polycystic Ovary Syndrome (PCOS) is one of the most common causes of an ovulatory infertility. The classification of the disease is based on both clinical and endocrine features with a well known ultrasound ovarian pattern, obesity, menstrual cycle disturbances, hyperandrogenaemia, chronic anovulation, abnormal gonadotrophin secretion and hyperinsulinemia ${ }^{[9,10]}$.

In 1910, Jacobeaus coined the term laparoscopy in his report of the exploration of the peritoneal cavity of 17 human with ascitis using a cystoscope without pneumoperitonum.

In 1938, Verss described a new needle for inducing pneumoperitioneum an instrument that continue to be commonly used today ${ }^{[11]}$.

Recently gasless laparoscopy was developed to reduce the risk of pneumoperitioneum ${ }^{[12]}$.

Laparoscopy can be used as therapeutic and diagnostic tools, especially for diagnosis of PCO and correct timing of the procedure will enable evidence of ovulation to be obtained ${ }^{[13]}$.

Treatment of some conditions can be undertaken during the same time of the diagnostic process as adhesiolysis for adhesions, laparoscopic diathermy for

Corresponding Author: Nabila K. Yaaqoub, Department of Gynecology and Obstetrics, College of Medicine, University of Tikrit, P.O. Box 42, Tikrit Salahuddin, Iraq 
PCO, aspiration of ovarian cyst and coagulation of endometriotic spots ${ }^{[14]}$.

The main complications of laparoscopy include damage to the gastro intestinal tract and abdominal wall vessles, post operative bowel herniation through the entry scars, complications of anesthesia and pneumoperitoneum ${ }^{[15]}$.

For many years, it has been known that surgical wedge resection for polycystic ovaries results in profound hormonal alterations resulting in the resumption of ovulation in a large number of patients. Unfortunately surgical treatment by laparoscopy results in peritubal and peri ovarian adhesions in a significant number of patients which can, in itself, result in infertility ${ }^{[16]}$.

The same surgical effect can be mimicked at laparoscopy by drilling multiple holes in the polycystic ovaries with electrodiathermy needle or one of the flexible fiber lasers. Controlled destruction of the androgen producing stroma and release of androgen rich fluid from the subcapsular cysts leads to a significant reduction of androstenedione, testosterone and dyhydrotestosterone within first 3 post operative days ${ }^{[4]}$.

Marked reduction in the mean lutenizing hormone level with a concomitant reduction in luteinizing hormone pulse amplitude, but no change in Luteinizing level ${ }^{[17]}$.

\section{MATERIALS AND METHODS}

The present study is a prospective study; a total of 40 infertile PCOS patients were seen in one year (from May 2008-2009). All the women fulfilled our criteria for diagnosis of PCOS.

A full history was obtained from each woman and a full physical examination was performed.

The selected patients had the following:

- Two or more of PCOS sign

- History of an ovulatory infertility

- $\quad$ oligomenorrhoea or amenorrhoea

- $\quad$ Elevated LH or LH\FSH ratio

- Increased ovarian volume and equal or more than 10 follicles of $2-8 \mathrm{~mm}$ in diameter by ultrasound examination.

- Tubal factors were excluded by hystero salpingography

- Normal seminal fluid analysis

All patients in this study were in reproductive age group between 20-40 years old. In this study the treatment protocol was planned in two groups:
- Group A: Include 20 patients were undergoing abdominal diathermy

- Group B: Include 20 patients were undergoing laparoscopic diathermy

None of those patients were treated with ovulation induction therapy in the previous 3 months.

From the ethical point of view all of patients were asked if they would like to participate in the study.

All the patients in this study had previously unresponded to ovulation induction drugs. The ovulatory response was assessed for both groups by measurement of LH and testosterone level after 10 days of post operative abdominal and laparoscopic diathermy.

\section{RESULTS}

The age of patients in both groups (group A and group B) ranged from 20-40 years with a mean of 29.5 years.

The duration of infertility in first group was from 2-8 years with a mean of 5.2 years and in the second group it was 1-10 years with a mean of 5.0 years.

The irregularity of menses in both groups before surgery was $100 \%$ as in Table 1.

The irregularity of menses in the first group was (75\%) and in second group was (40\%) after surgery.

After surgery there were significant effects on regularity of menses. In first group, $25 \%$ had regular cycle and in second group $60 \%$ had regular cycle as in Table 2.

Table 1: The Irregularity before surgery

\begin{tabular}{lcc}
\hline Group & Group A & Group B \\
\hline Age & 29.5 & 29.5 \\
Duration of infertility & 5.2 & 5.0 \\
Irregularity of cycle & 100.0 & 100.0 \\
\hline
\end{tabular}

Table 2: The Irregularity after surgery

\begin{tabular}{lccl}
\hline Type & Irregular cycle & Regular cycle & Total \\
\hline Abdominal diathermy & 15 & 5 & 20 \\
Laparoscopic diathermy & 8 & 12 & 20 \\
Total & 23 & 17 & 40 \\
\hline$X^{2}=5.08 ;$ Dr &
\end{tabular}

$\mathrm{X}^{2}=5.08 ; \mathrm{Df}=1 ; \mathrm{p}>0.05$, so there is a significant difference between abdominal and laparoscopic diathermy regarding the regularity of cycles

Table 3: The ovulatory response

\begin{tabular}{|c|c|c|c|c|}
\hline Type & $\begin{array}{l}\text { Decrease LH } \\
\text { and testosterone }\end{array}$ & No change & Total & Percent \\
\hline Abdominal diathermy & 7 & 13 & 20 & 35 \\
\hline Laparoscopic diathermy & 14 & 6 & 20 & 70 \\
\hline Total & 21 & 19 & 40 & \\
\hline
\end{tabular}


The ovulatory response by measuring $\mathrm{LH}$ and testosterone levels after 10 days of surgery was significantly different in the first group; it was 35\% and in second group it was (70\%) as in Table 3.

\section{DISCUSSION}

It is evident that PCOS is known to be a highly heterogeneous disorder with features including menstrual cycle irregularity, obesity, acne, hirsutism, subfertility and abnormal biochemistry including elevated testosterone androstenedione, LH and insulin $^{[18]}$.

All women in our study were in the reproductive age group and had variable clinical presentations especially irregular cycle and infertility as in Table 1.

The irregularity of menses after surgery in first group (abdominal diathermy) was $75 \%$ with irregular cycle and $25 \%$ of women with regular cycle; while in the second group (laparoscopic diathermy), $40 \%$ with irregular cycle and $60 \%$ with regular cycle. This means that the effects of laparoscopic diathermy on regularity of cycle were more significant than the effects of abdominal diathermy this which is consistent with the findings in ${ }^{[4]}$, as in Table 2.

In our study, $35 \%$ of the first group patients after treatment had decrease in $\mathrm{LH}$ and testosterone levels and $70 \%$ of the second group patients after treatment had decrease in LH and testosterone levels as in Table 3 which is consistent with Sumioki study ${ }^{[17]}$.

Unfortunately, these biochemical changes are very important factors for evaluating patients with PCOS regarding rates of ovulation and pregnancy in future ${ }^{[19,20]}$.

\section{CONCLUSION}

- Abdominal and laparoscopic diathermy both can be used in PCOS patients

- Laparoscopic diathermy had a better effects than abdominal diathermy on ovulatory process in patients with PCOS

\section{REFERENCES}

1. Ash Monga and P. Baker, 2006. Gynecology by Ten Teachers. 18th Edn., Oxford University Press, Oxford, ISBN: 13: 978-0-340-81662-2, pp: 84-93.

2. Johnson, M.H. and B.J. Everitt, 2000. Essential Reproduction. 5th Edn., Blackwell Science Ltd., Oxford, ISBN: 0-632-04287-7.

3. Bartinos, M.L., 1993. Diagnostic dilemmas in polycystic ovary syndrome. Ann. Acad. Sci., 687: $230-234$. DOI: $10.1111 / \mathrm{j} .1749-$ 6632.1993.tb43870.x
4. Dewhurst, J. and D. Edmonds, 1999. Dewhursts Text Book of Obestetric and Gyanecology for Post Graduates. 6th Edn. John Wiley and Sons, Oxford, ISBN: 0865426511, pp: 42-59.

5. Bereck, J.S., 1996. Infertility. Berek and Novaks Gyanecology. 14th Edn., Lippincott Williams and Wilkins, ISBN: 0683005936, pp: 915-926.

6. Polson, D.W., J. Adams, J. Wadsworth and S. Franks, 1988. Polycystic ovaries-a common finding in normal women. Lancet, 1: 870-872. PMID: 2895373

7. Clayton, R.N., V. Ogden, Hodgkinsonj, L. Worswick, D.A. Rodin and Dyers et al., 1992. How common are poly cystic ovaries in normal women and what is their significance for the infertility of the population? Clin. Endocrinol. (Oxf.), 37: 127-134. PMID: 1395063

8. Solomon, C.G., 1999. The epidemiology of polycystic ovary syndrome. Prevalence and associated disease risks. Endocrinol. Metab. Clin. North Am., 28: 247-263. PMID: 10352918

9. Goldenberg N. and C. Glueck, 2008. Medical therapy in women with polycystic ovarian syndrome before and during pregnancy and lactation. Minerva Ginecol., 60: 63-75. PMID: 18277353

10. Doldi, N., E. Marsiglio, A. Alessandro Destefani, A. Alessandra Gessi, G. Merati and A. Ferrari, 1999. Destefan: Elevated serm progesterone on the day of HCG administration in IVF is associated with higher pregnancy rate in polycystic ovary syndrome. Hum. Reprod., 14: 601-605. DOI: 10.1093/humrep/14.3.601

11. Wein, A., L. Kavoussi, C. Peters, A. Novick and A. Partin, 2007. Campbell-Walsh Urology. Saunders WB Co., ISBN: 1416031553.

12. Bin, L., H. Jingning, G. Xiuzhen, L. Tao, Z. Jun and W. Hong, et al. 2001. Gynecological procedures under gasless laparoscopy. Chinese Med. J., 114: 514-516. http://www.cmj.org/Periodical/PaperList.asp?id=L W8018

13. Charikleia, D., E. Kandarakis, 2008. Role of androgen excess on metabolic aberrations and cardiovascular risk in women with polycystic ovary syndrome. Women's Health, 4: 583-594. DOI: 10.2217/17455057.4.6.583

14. The ESHRE Capri Workshop Group, 2000. Optimal use of infertility diagnostic tests and treatment. Hum. Reprod., 15: 723-732. DOI: 10.1093/humrep/15.3.723 
15. Shirk, G.J., A. Johsn and D. Redwine, 2006. Complications of laparoscopic surgery: How to avoid them and how to repair them. J. Minim. Invasive Gynecol., 13: 352-359. DOI: 10.1016/J.JMIG.2006.03.020

16. Keith, E.D. and D. John, 1999. Dewhurst's Text Book of Obstetrics and Gynaecology for Post Graduates. 6th Edn., Blackwell Science, Oxford, UK., ISBN: 086542652X, pp: 505-521.

17. Tasaka, S.M., H. Kurachi, N. Terakawa, A. Miyak and O. Tanizawa, 1990. Changes of bioactive luteinizing hormone after laparoscopic ovarian cautery in patients with polycystic ovarian syndrome. Fertil. Steril., 53: 610-613. PMID: 2138570
18. Mairtra, A., P. Meherji, J. Gokral, U. Donde and U. Joshi, 1994. Lipoprotein lipids in androgen excess-a study among Indian women. Int. J. Fertil. Menopausal Stud., 39: 218-222. PMID: 7951405

19 Eckmann, K., 2009. Aromatase Inhibitors for ovulation and pregnancy in polycystic ovary syndrome. Ann. Pharmacother., 43: 1338-1346. DOI: 10.1345/aph.1M096

20. Pasic, R.P. and R.L. Levine, 2007. Practical Manual of Laparoscopy and Minimally Invasive Gynecology: A Clinical Cookbook. 2nd Edn., Taylor and Francis, ISBN: 10: 184214 3301, UK. 